\title{
RANCANGAN MANAJEMEN FILING DAN DESAIN FORMULIR PELAYANAN KESEHATAN UMUM DI PUSKESMAS SUNYARAGI KOTA CIREBON
}

\author{
Sri Nani Purwaningrum ${ }^{1}$, Lina Khasanah ${ }^{2}$, Bambang Karmanto ${ }^{3}$ \\ ${ }^{1,2,3}$ Poltekkes Kemenkes Tasikmalaya, Cirebon \\ srinani.purwaningrum@gmail.com
}

Diterima:

Direvisi:

Diterbitkan:

\begin{abstract}
Filing or storage of medical record documents is a Medical Record work unit that functions as a place for regulating and storing medical record documents on the basis of certain structuring systems through systematic procedures, so that at any time it can be presented quickly and accurately. The purpose of this activity is to rearrange the storage of the patient's medical record so that the rack is filled evenly and make predictions on the amount of medical record storage on the shelf to make the place more efficient. The methods used were advocacy to the puskesmas, identification and needs analysis of filing arrangement and design of medical record form maps, design of medical record form map designs, trial design of medical record form maps, socialization, and evaluation. The results obtained are medical record filing arrangements, 200 maps of medical record forms of health examination services and SPO of storing medical records of patients at the Sunyaragi Health Center.
\end{abstract}

Keywords: $\quad$ Filing Management Design, Design of General Health Service Form, Sunyaragi Health Center

\begin{abstract}
ABSTRAK
Filing atau penyimpanan dokumen rekam medis adalah unit kerja Rekam Medis yang berfungsi sebagai tempat pengaturan dan penyimpanan dokumen rekam medis atas dasar sistem penataan tertentu melalui prosedur yang sistematis, sehingga sewaktu waktu dibutuhkan dapat menyajikan secara cepat dan tepat. Tujuan kegiatan ini Mengatur kembali penyimpanan rekam medis pasien sehingga rak terisi secara merata dan membuat prediksi jumlah penyimpanan rekam medis di rak untuk mengefisiensikan tempat. Metode yang dilakukan adalah advokasi ke puskesmas, identifikasi dan analisis kebutuhan penataan filing dan desain map formulir rekam medis, perancangan desain map formulir rekam medis , ujicoba desain map formulir rekam medis, sosialisasi, dan evaluasi. Hasil yang diperoleh penataan filing rekam medis, 200 map formulir rekam medis pelayanan pemeriksaan kesehatan dan SPO penyimpanan rekam medis pasien di Puskesmas Sunyaragi.
\end{abstract}

Kata Kunci : Rancangan Manajemen Filing, Desain Formulir Pelayanan Kesehatan Umum, Puskesmas Sunyaragi 


\section{PENDAHULUAN}

Rekam medis merupakan berkas yang berisikan catatan dan dokumen tentang identitas pasien, pemeriksaan, pengobatan, tindakan dan pelayanan lain kepada pasien pada sarana pelayanan kesehatan (1). Rekam medis sangat penting dalam pelayanan bagi pasien karena selain dapat memberikan informasi untuk menentukan keputusan dalam pengobatan, penanganan, serta tindakan medis, tetapi juga mempunyai peranan yang sangat penting dalam aspek hukum dimana rekam medis dapat menjadi alat bukti tertulis untuk menyelesaikan perkara hukum (3). Salah satu penyelenggaraan rekam medis dalam pelayanan kesehatan yaitu filing, dimana filing adalah kegiatan menyimpan, penataan atau penyimpanan (storage) berkas rekam medis untuk mempermudah pengambilan kembali (Retrieval) (8). Puskesmas merupakan garda depan dalam penyelenggaraan upaya kesehatan dasar. Puskesmas dapat menjalankan fungsinya secara optimal harus dikelola secara optimal baik kinerja pelayanan, proses pelayanan, maupun sumber daya yang digunakan. Masyarakat menghendaki pelayanan kesehatan yang aman dan bermutu, serta dapat menjawab kebutuhan mereka, oleh karena itu upaya peningkatan mutu, manajemen risiko dan keselamatan pasien perlu diterapkan dalam pengelolaan Puskesmas. Untuk menjamin bahwa perbaikan mutu, peningkatan kinerja dan penerapan manajemen risiko dilaksanakan secara berkesinambungan di Puskesmas, maka perlu dilakukan penilaian oleh pihak eksternal dengan menggunakan standar yang ditetapkan yaitu melalui mekanisme akreditasi (Kementerian Kesehatan RI, 2015).Prinsip dari pelayanan kesehatan yang bermutu adalah keberpihakan terhadap pelanggan. Dua hal yang perlu dipantau dalam upaya perbaikan mutu adalah kepuasan pelanggan dan standar pelayanan kesehatan yang harus dilakukan secara seimbang (6). Pelaksanaan sistem penyimpanan rekam medis di Puskesmas Sunyaragi belum sepenuhnya berjalan dengan lancar dikarenakan ada beberapa rekam medis pasien yang duplikasi, miss file (salah menyimpan), rak penyimpanan tidak terisi secara merata dan untuk desain formulirnya, puskesmas sunyaragi akan mendesain ulang rekam medis yang sudah ada dengan alasan belum mewakili seluruh pelayanan yang ada untuk pengisiannya. Hal ini menjadikan persoalan bagi petugas rekam medis karena dapat berpengaruh kepada kecepatan dan ketepatan pelayanan di pendaftaran Puskesmas Sunyaragi. Pelaksanakan kegiatan filing harus didukung dengan sarana diantaranya rak file, dimensi folder dan ruang penyimpanan yang memadai. Desain rak file seharusnya disesuaikan dengan antropometri orang Indonesia dan dimensi dokumen rekam medis. Antropometri yang digunakan antra lain jangkauan tangan keatas yaitu sebagai acuan tinggi rak file dan panjang depan untuk panjang rak (7).

\section{METODE}

Metode dalam pelaksanaan kegiatan ini berupa identifikasi dan diskusi melalui wawancara. Adapun tahapan kegiatan yang dilakukan antara lain:

1. Advokasi kepada pihak Puskesmas Sunyaragi. Sasaran dalam kegiatan ini adalah kepala puskesmas, petugas rekam medis dan petugas pada setiap unit pelayanan yang ada di Puskesmas Sunyaragi yaitu unit pemeriksaan umum, pelayanan KIA/KB dan pelayanan kesehatan gigi. Kegiatan ini ditujukan untuk mendapatkan dukungan dalam pelaksanaan kegiatan.

2. Identifikasi kebutuhan isi formulir rekam medis untuk membuat desain map formulir rekam medis, penataan rak filing, dan penyusunan SPO penyimpanan rekam medis 
yaitu dengan brainstorming dengan Kepala Puskesmas, petugas rekam medis dan petugas di unit pelayanan pemeriksaan umum, pelayanan KIA/KB dan pelayanan kesehatan gigi. .

3. Analisis kebutuhan terkait hasil identifikasi, untuk disesuaikan dengan teori maupun regulasi yang ada. Setelah mendapatkan kesesuaian antara kebutuhan puskesmas dengan teori/regulasi, selanjutnya item-item tersebut ditindaklanjuti dengan tahapan kegiatan perancangan desain map formulir rekam medis, penataan filing dan penyusunan SPO penyimpanan rekam medis.

4. Uji Coba penerapan map formulir rekam medis dan SPO penyimpann rekam medis yang sudah tersusun pada filing rekam medis dengan menggunakan sistem SNF.

5. Sosialisasi. Desain map formulir rekam medis dan SPO penyimpanan rekam medis yang sudah tersusun dilakukan sosialisasi kepada seluruh petugas Puskesmas Sunyaragi untuk memperoleh konfirmasi masukan perbaikan dan kesepakatan final.

6. Evaluasi. Pada tahap evaluasi ini dilakukan monitoring penerapan SPO filing pada pelaksanaan penyimpanan rekam medis menggunakan sistem SNF, penataan sesuai standar manajemen filing dan selanjutnya monitoring uji coba penerapan desain formulir pelayanan umum di Puskesmas Sunyaragi.

\section{HASIL DAN PEMBAHASAN}

\section{Mengatur kembali penyimpanan rekam medis pasien}

\section{a. Penjajaran rekam medis sesuai metode yang diterapkan}

Puskesmas sunyaragi memakai sistem penjajaran SNF, hal ini dilihat dari kebutuhan dan ketersediaan tempat penyimpanan dokumen rekam medis yang ada di PuskesmasSunyaragi.

\section{b. Menyisir rekam medis pasien yang miss file dan ganda}

Penyisiran dilakukan pada kolom Nomor rekam medis 0001-1000 dan 4001-5000 dan ditemukan limabelas (15) rekam medis yang mengalami miss file (salah simpan). Sedangkan untuk dokumen rekam medis yang mengalami penggandaan nomor rekam medis ditemukan sejumlah sembilan puluh enam (96) rekam medis. Penggandaan rekam medis yang dimaksud adalah bahwa dalam satu nomor rekam medis terdapat 2 atau lebih nama pasien. Hal ini disebabkan kesalahan petugas rekam medis yang terdahulusebelum adanya pergantian petugas rekam medis yang baru, yaitudalam memberikan nomor rekam medis pada pasien baru sering meggunakan nomor rekam medis pasien lama.Redudansi rekam medis ini terjadi dalam rentang waktu lama, dan selanjutnya tidak dilakukan penyisiran kembali dokumen rekam medis pasien baru untuk diperbaharui nomor rekam medisnya untuk digantikan dengan nomor rekam medis baru (nomor rekam medis pasien lama dipakai untuk pasien baru)

\section{a. Menata rekam medis secara proporsional untuk setiap sectionrak penyimpanan}

melakukan penataan filing dengan merapikan rekam medis yang tidak beraturan di lemari penyimpanan agar memudahkan pencariandan penyimpanan kembali rekam medis yang telah digunakan (Retrieve)

\section{Membuat/mendesain rekam medis pelayanan pasien}

\section{a. Pembuatan desain map formulir rekam medis dilakukan denganbeberapa tahap :}

- Tahap pertama :

Konsultasi dengan pihak Puskesmas Sunyragi untuk mengidentifikasi kebutuhan terkait penataan rekam medis

- Tahap kedua : 
Petugas RM mengirim desain awal map formulir rekam medis kepada timpengabmas

- Tahap ketiga :

Mendesain dan menambahkan item-item yang kurang pada desain formulir yang telah dibuat oleh pihak Puskesmas.

- Tahap Finalisasi :

- $\quad$ Penyempurnaan desain formulir yang disepakati kedua belah pihak

Bahan map rekam medis menggunakan jenis kertas concordedengan ketebalan 160 gr, spesifikasi panjang $21,5 \mathrm{~cm}$ dan lebar $16,5 \mathrm{~cm}$ dengan menggunakan jenis kertas concorde.

b. Desain map formulir rekam medis pelayanan pemeriksaan kesehatan

b.1. Desain Awal

\begin{tabular}{|c|c|c|}
\hline Desain Map 1 & & \\
\hline 팔 & $\begin{array}{c}\text { PEMERINTAH DAERAH KOTA CIREBON } \\
\text { DINAS KESEHATAN } \\
\text { UPT PUSKESMAS SUNYARAGI } \\
\text { II. Evakuasi No 01. No. Telp. (0231) } 482543\end{array}$ & $\begin{array}{l}\mathrm{NO} . \\
\mathrm{RM}\end{array}$ \\
\hline \multicolumn{3}{|l|}{ RAHASIA } \\
\hline \multicolumn{2}{|r|}{ REKAM MEDIS } & \\
\hline NAMA & & \\
\hline UMUR/TANGGAL. LAHIR & & \\
\hline JENIS KELAMIN & & \\
\hline ALAMAT & & \\
\hline TIDAK DI & $\begin{array}{l}\text { KUMEN INI MILIK PUSKESMAS SUNYARAGI } \\
\text { ENANKAN ENTUK DIBAWAKFLUAR DARI PUSKESMAS }\end{array}$ & \\
\hline
\end{tabular}


b.2. Perbaikan desain tahap 1

\begin{tabular}{|c|c|c|}
\hline 20.73 & $\begin{array}{c}\text { PEMERINTAH DAERAH KOTA CIREBON } \\
\text { DNNAS KESEHATAN } \\
\text { UPT PUSKESMAS SUNYARAGI } \\
\text { J1. Evakaasi No. 01 No. Telp-(0231) } 48254 \\
\text { Kel. Sunyaragi Kec, Kesambi Kota Cirebon }\end{array}$ & $\begin{array}{l}\mathrm{NO} \\
\mathrm{RM}\end{array}$ \\
\hline \multicolumn{3}{|l|}{ RAHASIA } \\
\hline \multicolumn{2}{|r|}{ REKAM MEDIS } & \\
\hline NAMA & $=$ & \\
\hline TANGGAL LAHIR/UMUR & LP & \\
\hline ALAMAT & 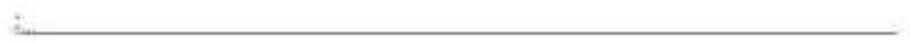 & \\
\hline JAMINAN KESEHATAN & $\therefore \quad \mathrm{NO}:$ & \\
\hline \multicolumn{2}{|c|}{$\begin{array}{l}\text { TIDAK DIPERKENANKAN UNTUK DIBAWAKELUAR DARI PUSKESMLAS } \\
\text { SETELAH SELESAI DIPERGUNAKAN SEGERA DIKEMBALIKAN }\end{array}$} & \\
\hline
\end{tabular}

b.3. Perbaikan desain tahap 2

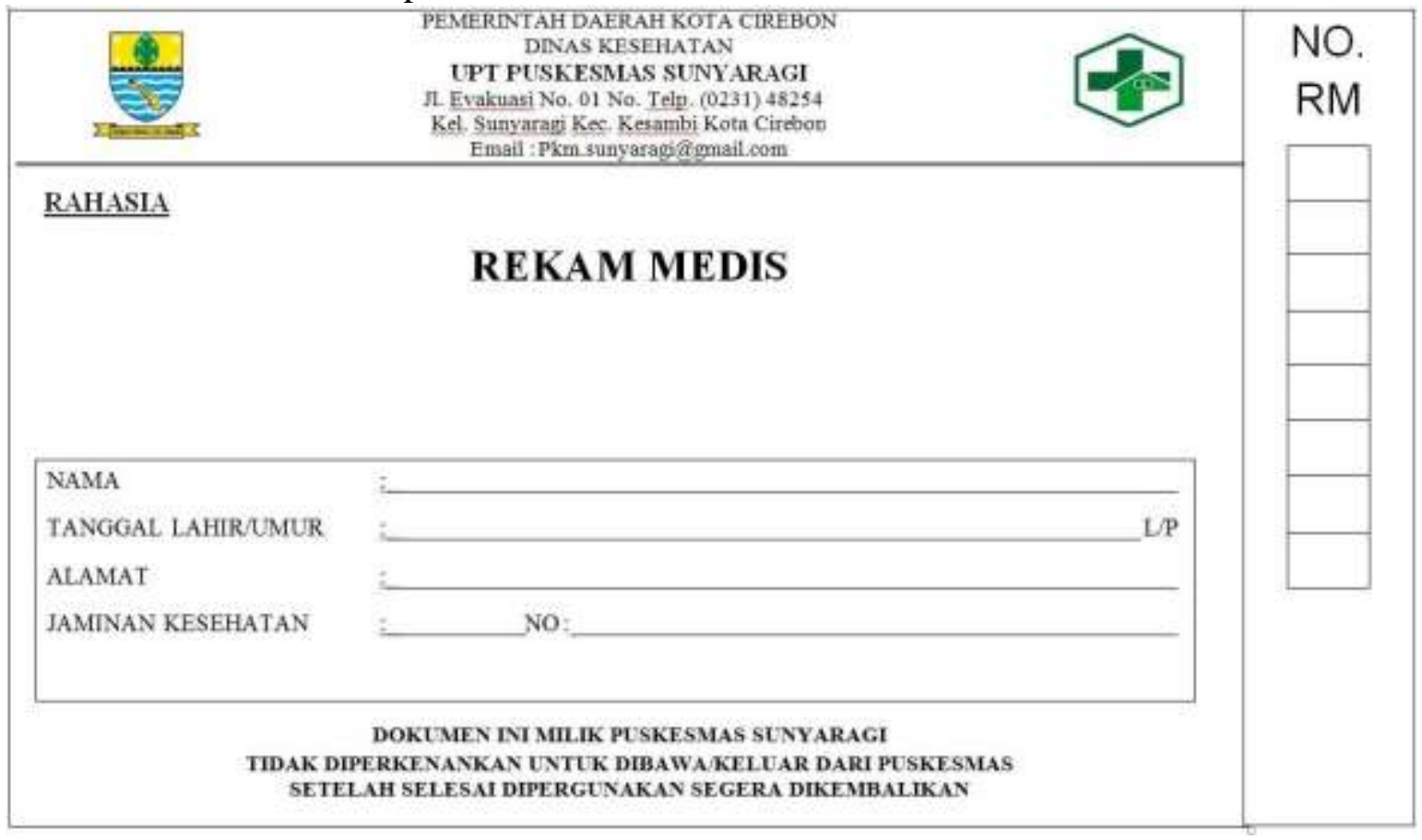


b.4. Finalisasi desain

\begin{tabular}{|c|c|}
\hline 28 & $\begin{array}{l}\text { MERINAH DAERAH KOTA CRREBON } \\
\text { DINAS KESEHATAN } \\
\text { TPT PUSKESMAS SUNYARAGI } \\
\text { Evakuasi No. 01 No. Telp. (0231) } 482543 \\
\text { 1. Sunyaragi Kec. Kesambi Kota Cirebon } \\
\text { Email : Pkm sunyaragi Qgmail com }\end{array}$ \\
\hline \multicolumn{2}{|l|}{ RAHASIA } \\
\hline $\begin{array}{l}\text { NAMA } \\
\text { TANGGAL LAHIR/UMUR } \\
\text { ALAMAT } \\
\text { JAMINAN KESEHATAN }\end{array}$ & No: LP \\
\hline $\begin{array}{l}\text { DOK } \\
\text { TIDAK DIPERKE } \\
\text { SETELAH SE }\end{array}$ & $\begin{array}{l}\text { EN INI MILIK PUSKESMLS SUNYARAGI } \\
\text { NKAN UNTUK DIBAWA/KEICAR DARI PUSKESMIS } \\
\text { SAI DIPERGUNAKAN SEGERA DIKEMBALIKANS }\end{array}$ \\
\hline
\end{tabular}

\section{Membuat SPO penyimpanan rekam medis pasien}

Dalam penyelenggaraan penyimpananrekam medis pasien di Puskesmas Sunyaragi perlu disusun Standar Prosedur Operasional untuk menjamin standarisasi mutu rekam medis sesuai dengan ketetapan regulasi yang mengatur tentang penyelenggaraan rekam medis yaitu Peraturan Menteri Kesehatan Republik Indonesia No.269 tahun 2008 Bab IV pasal 9 dan Pedoman Penyelenggaraan dan Prosedur Rekam Medis Depkes RI Tahun 2006.

\section{SIMPULAN}

Mengatur kembali penyimpanan rekam medis pasien, Penjajaran rekam medis menggunakan sistem Straight Numerical Filing(SNF), Penyisiran rekam medis pasien ditemukan miss file rekam medis sebesar $0,3 \%$ dan redudandi rekam medis sebesar 1,2\%, Penataan rekam medis secara proporsional untuk setiap section rak penyimpanan tidak ditemukan dokumen rekam medi dalam kondisi rusak. Membuat/mendesain rekam medis pelayanan pasien dengan realisasi cetak map sebesar 200 map rekam medis. Membuat SOP penyimpanan rekam medis pasien dengan realisasi satu (1) dokumen SPO manajemen filing rekam medis dan alur penyimpanan rekam medis pasien 


\section{DAFTAR PUSTAKA}

1. Depkes RI. (2006). Pedoman Penyelenggaraan dan Prosedur Rekam Medis Rumah Sakit.Jakarta: Direktorat Jendral Bina Pelayanan Medik.

2. Gondodiputro, Sharon. 2017. Rekam Medis dan Sistem Informasi Kesehatan di Pelayanan Kesehatan Primer (Puskesmas). Jurnal Unpad.

http://resources.unpad.ac.id/unpadcontent/uploads/publikasi_dosen/Rekam\%20Medis\%20dan\%20SIK.PDF.BANDUNG: UNPAD

3. Hatta, Gemalla R. (2008).Pedoman Manajemen Informasi Kesehatan di Sarana Pelayanan Kesehatan. (edisi revisi). Jakarta: Universitas Indonesia.

4. Hutasuhut, Rini Maharani. (2016). Pengaruh Aspek Ergonomi Ruang Penyimpanan terhadap Kecepatan Penyediaan Pelayanan Dokumen Rekam Medis di Rumah Sakit Umum Tapanuli Selatan.Agustus 5, 2016.Akademi Perekam Medik dan Informasi Kesehatan Imelda Medan. http://www.apikesimelda.ac.id(diakses tanggal 27 Januari 2017)

5. Menteri Kesehatan R.I. (2008).PermenkesNomor 269/Menkes/Per/III/2008 TentangRekamMedis.Jakarta: Kemenkes RI

6. Menteri Kesehatan Republik Indonesia. 2015. Peraturan Menteri Kesehatan Republik Indonesia No 46 Tahun 2015 Tentang Akreditasi Puskesmas, Klinik Pratama, Tempat Praktik Mandiri Dokter dan Tempat Praktik Mandiri Dokter Gigi. Jakarta : Kementerian Kesehatan

7. Rozikin, Khoerur. (2013, Oktober 23). Tinjauan Keergonomisan Ruang Filing rawat Inap di RSUD Kota Semarang. Rekam Medis dan Informatika kesehatan. Februari 11, 2017. http://eprints.dinus.ac.id/id.eprint/7896

8. Rustianto, E. dan Rahayu, W, A. (2011). Manajemen Filling Dokumen Rekam Medis dan Informasi Kesehatan. Yogyakarta: Graha Ilmu. 